\title{
Critérios para Habilitação à Adoção segundo Técnicos Judiciários
}

\author{
Patricia Santos da Silva \\ Monique Souza Schwochow ${ }^{1}$ \\ Gabriela de Faria Resmini ${ }^{1}$ \\ Giana Bitencourt Frizzo ${ }^{1}$ \\ ${ }^{1}$ Universidade Federal do Rio Grande do Sul - UFRGS, Porto Alegre, Rio Grande do Sul, Brasil
}

\begin{abstract}
Resumo
A adoção é forma de possibilitar uma família às crianças e aos adolescentes privados do convívio familiar. Candidatos à adoção devem passar por um processo de avaliação e preparação, orientado pelas equipes técnicas dos Juizados da Infância e Juventude. Os profissionais devem avaliar questões complexas sobre adoção e parentalidade, porém a falta de um critério norteador pode trazer dificuldades nas avaliações. Diante disso, o presente estudo teve como objetivo descrever os critérios utilizados por técnicos judiciários do Rio Grande do Sul nos processos de habilitação para adoção. Realizou-se entrevistas com psicólogos e assistentes sociais de sete cidades do estado. Por meio da análise de conteúdo, identificou-se que se deve avaliar questões relativas à história de vida, características pessoais, relações familiares e sociais e as motivação para a parentalidade. Discute-se que os processos de habilitação podem ser pensados como um espaço de reflexão acerca do projeto de adoção e de parentalidade dos adotantes além de somente uma avaliação.
\end{abstract}

Palavras-chave: processos legais, avaliação psicossocial, psicologia jurídica

Criteria for habilitation for adoption according to judicial technicians

\section{Resumen}

Adoption is a way of enabling children and adolescents deprived of family life to have a family. Adoption candidates must undergo a process of evaluation and preparation, guided by the technical teams of the Child and Youth Courts. Professionals should evaluate complex questions about adoption and parenting, but the lack of a guiding criterion can lead to difficulties in this process. Thus, the present study aimed to describe the criteria used by judicial technicians of the state of Rio Grande do $\mathrm{Sul}$ in the qualification processes for adoption. Interviews were conducted with psychologists and social workers from 7 cities in the state. The content analysis identified that issues related to life history, personal characteristics, family and social relationships, and motivation for parenting should be evaluated. It is argued that the qualification process can be thought of as a space for reflection on the adoption project and the parenting of the adopters besides only an evaluation.

Keywords: legal processes; psychosocial evaluation; forensic psychology

\section{Criterios para habilitación a adopción según técnicos judiciales}

\section{Resumen}

La adopción es una forma de propiciar una familia para niños y jóvenes privados de la vida familiar. Los candidatos a adopción deben someterse a un proceso de evaluación y preparación, guiados por los equipos técnicos de los tribunales de la infancia. Los profesionales deben evaluar preguntas complejas sobre la adopción y la crianza de los hijos, pero la falta de un criterio rector puede llevar a dificultades en las evaluaciones. Ante esto, el presente estudio tuvo como objetivo describir los criterios utilizados por los técnicos judiciales de Rio Grande do Sul en los procesos de calificación para la adopción. Se realizaron entrevistas con psicólogos y trabajadores sociales de siete ciudades del estado. Así a través del análisis del contenido, se deben evaluar las cuestiones relacionadas con la historia de la vida, las características personales, las relaciones familiares y sociales, y la motivación para la crianza de los hijos. Se argumenta que los procesos de calificación pueden considerarse como un espacio para reflexión sobre el proyecto de adopción y la crianza de los adoptantes, así como sólo una evaluación.

Palabras clave: procesos legales; evaluación psicosocial; psicología jurídica.

\section{Introdução}

A adoção é uma forma de estabelecimento de relações de paternidade e de maternidade entre pessoas sem vínculos consanguíneos. Tem por objetivo primordial a inserção de uma criança em uma unidade familiar, quando a família biológica não tem como prover as condições necessárias ao seu desenvolvimento.
Segundo Sprince, Hindle e Shulman (2008), a adoção envolve uma constelação de forças emocionais distintas e complexas, como a família de origem, a criança e a família adotiva, as leis e o sistema legal, uma rede profissional, o conjunto de valores e crenças sociais e culturais, além da ideologia e dos mitos que envolvem o tema. Ainda, é importante destacar que, na base de toda adoção, há uma história de rompimento precoce dos 
vínculos afetivos da criança com a família de origem e a disponibilidade e o desejo de um adulto de ser pai ou mãe (Chaves, 2008).

Sobre o aspecto emocional na adoção, pode-se inferir que ocorrem processos paralelos, porém, distintos. De um lado, encontra-se a perda dos laços primários de uma criança, privada da convivência com sua família de origem (Chaves, 2008) e, de outro lado, na maioria das vezes, a impossibilidade do adotante de gerar filhos biológicos (Morelli, Scorsolini-Comin, \& Santeiro, 2015; Rampage et al., 2016). Pode-se, então, afirmar que a perda é um tema presente desde o início da adoção, sendo um aspecto importante na avaliação dos profissionais que trabalham com a seleção de candidatos à adoção (Rampage et al., 2016). De acordo com esses autores, os profissionais defendem que a elaboração da perda causada pela infertilidade e, consequentemente, o luto pelo filho idealizado desejado devem ser processos anteriores à adoção, porém, a literatura sobre o tema ainda é bastante controversa (Silva, 2015).

No Brasil, a partir do desejo de adotar um filho, existe a possibilidade de solicitar, junto ao judiciário, nos juizados da infância e da juventude (JIJ), um processo de habilitação para adoção. Com a criação do processo, ele é encaminhado diretamente à equipe técnica para avaliação psicossocial que dará subsídios à decisão judicial. Por meio desta, a equipe tem um papel importante para verificar as condições dos possíveis adotantes a fim de tentar evitar que haja um retorno da criança ou adolescente à instituição de acolhimento após a adoção (Riede \& Sartori, 2013). Para isso, psicólogos e assistentes sociais se utilizam dos instrumentos que julgarem cabíveis para avaliação, cuja duração vai depender das particularidades de cada caso.

Embora o Estatuto da Criança e do Adolescente - ECA (Estatuto da Criança e do Adolescente, 1990) determine a necessidade de avaliação e preparação dos adotantes, não descreve de forma específica os critérios que devem ser estudados nesse processo. Diz apenas que a adoção não deve ser deferida à "pessoa que revele, por qualquer modo, incompatibilidade com a natureza da medida [de proteção] ou não ofereça ambiente familiar adequado" (ECA, 1990, Art. 29), mas sem esclarecer o que seria tal incompatibilidade ou ambiente familiar adequado.

A necessidade de um corpo teórico específico que fundamente a prática profissional no judiciário levou alguns autores a propor critérios e instrumentos que podem ser utilizados nessas avaliações (Paiva, 2004; Reppold, Chaves, Nabinger, \& Hutz, 2005). Sobre os instrumentos, os autores apontaram a possibilidade de utilizar, conforme a necessidade de cada caso, entrevistas conjuntas com os requerentes, entrevistas individuais, entrevistas com filhos ou outros familiares, visitas domiciliares, escalas psicométricas e testes psicológicos e discussão em equipe. Com relação ao que deve ser investigado, esses mesmos autores citaram aspectos relacionados a diversas áreas psicossociais da família candidata como a estabilidade e estrutura psíquica e emocional dos integrantes, experiências familiares e de vida, crenças e expectativas com relação ao filho a ser adotado e a compreensão de aspectos relacionados à adoção e à história anterior do adotado. Além disso, alguns deles ainda enfatizaram a necessidade de se avaliar as motivações que levaram os candidatos à busca pela adoção (Cecílio \& Scorsolini-Comin, 2018; Morelli et al., 2015; Reppold et al., 2005).

Alguns questionamentos que ainda se fazem presentes em relação aos processos de habilitação se relacionam com a necessidade de se avaliar as condições das pessoas para a parentalidade, visto que é algo que não acontece na filiação biológica. Esse é um dos principais questionamentos dos pretendentes à adoção, inclusive. Em relação à transição para a parentalidade de maneira geral, percebe-se que é um processo complexo que se inicia muito antes da concepção e da chegada do filho, envolvendo as experiências dos pais desde suas primeiras relações pais-bebê, a atividade lúdica infantil, a adolescência, o desejo de ter um filho e a gravidez propriamente dita (Zornig, 2012). Cecílio e Scorsolini-Comin (2016) e Morelli, Scorsolini-Comin e Santeiro (2015) apontaram a necessidade da "gestação de um novo papel". Os autores salientaram que, nesse importante momento do ciclo vital, é preciso dedicar-se aos ajustes e adaptações que as novas tarefas e necessidades da parentalidade irão exigir. Os pais precisariam aprender, na rotina com a criança, seus papéis enquanto pais. Para Zornig (2010), a história se co-construiria entre as crianças e os adultos como produto das interações.

Apesar da existência de literatura específica sobre adoção, é possível perceber que o interesse dado a este tema na academia ainda é incipiente, apesar de estar aumentando nos últimos anos. Os trabalhos sobre adoção e sobre a avaliação de candidatos citados são, em sua maioria, manuais direcionados aos profissionais, construídos pelas equipes técnicas dos JIJ, sendo a literatura científica nacional ainda pouco profícua acerca das avaliações de pretendentes à adoção (Cecílio \& Scorsolini-Comin, 2018). Além disso, acredita-se que os critérios utilizados possam ser diferentes de acordo 
com a experiências cada profissional. Em função disso, tendo em vista a complexidade dos temas abordados no estudo psicossocial para habilitação para adoção e dificuldade de uma avaliação de candidatos à parentalidade ainda antes do contato com a criança, o presente estudo teve como objetivo identificar os critérios utilizados por técnicos judiciários para considerar um candidato habilitado para ser pai e/ou mãe adotivos. Mais especificamente, bem como conhecer as práticas e as condições de trabalho nas comarcas investigadas.

\section{Método}

\section{Participantes}

Participaram do estudo sete psicólogos e 10 assistentes sociais judiciários de sete cidades do Rio Grande do Sul que trabalhavam nos Juizados de Infância e Juventude (JIJ) do Estado na avaliação de candidatos nos processos de habilitação para adoção. Os profissionais eram formados há um período médio de 24 anos $(D P=7,13)$ e trabalhavam no judiciário há uma média de 14 anos $(D P=9,65)$, mínimo quatro meses e máximo 28 anos de experiência no judiciário. As mulheres representaram 94\% dos participantes.

\section{Delineamento e Procedimentos}

Foi utilizado um delineamento de estudo qualitativo exploratório (Robson, 2002), a fim de identificar como assistentes sociais e psicólogos judiciários do estado realizam avaliações de candidatos à adoção, os critérios utilizados e suas condições de trabalho. Primeiramente, todos os profissionais do estado foram contatados por e-mail a fim de se verificar o interesse e a disponibilidade em participar da pesquisa. Essa lista de contatos foi obtida por meio dos grupos de discussão dos psicólogos e assistentes sociais judiciários. No Rio Grande do Sul, esses profissionais realizam reuniões mensais em Porto Alegre para discussão de temáticas pertinentes a cada área. Todos aqueles que se dispuseram a participar do estudo e foram autorizados pelo respectivo juiz, que assinou um Termo de Ciência do Responsável pelo Local onde Será Realizada a Pesquisa, assinaram o Termo de Consentimento Livre e Esclarecido. As entrevistas foram realizadas nos locais de trabalho dos participantes.

O presente estudo seguiu os princípios éticos da resolução 466 de 2012, do Conselho Nacional de Saúde. O estudo foi aprovado pelo Comitê de Ética em Pesquisa do Instituto de Psicologia da UFRGS, sob o protocolo 17814113.3.0000.5334.

\section{Instrumentos}

Entrevista de Dados Profissionais. Relacionada à formação profissional, ao tempo de trabalho na comarca, aos tipos de processos atendidos e ao incentivo à capacitação profissional percebido pelo participante.

Entrevista sobre o processo de habilitação para adoção - versão psicólogos e versão assistentes sociais. Entrevistas semiestruturadas, elaboradas para este estudo, que trataram dos temas referentes ao fluxo dos processos em cada comarca, participação dos profissionais nos processos de habilitação, avaliação de candidatos à adoção conforme a especialidade profissional, critérios utilizados em tais avaliações e os aspectos investigados.

\section{Análise dos Dados}

As entrevistas foram gravadas em áudio digital e transcritas posteriormente. Os dados provenientes das entrevistas foram analisados por meio da análise de conteúdo descritiva (Bardin, 2011; Laville \& Dione, 1999) e as categorias foram criadas a partir da leitura do material coletado. A análise foi realizada com o auxílio do software NVivo versão 10 para a categorização e organização das informações coletadas. Os dados foram classificados em duas principais categorias a partir dos dados e da literatura revisada (Levinzon, 2014): Caracterização dos processos de habilitação e funcionamento das equipes; e Critérios Avaliados. A categoria Critérios Avaliados teve como subcategorias: (a) história de vida; (b) características pessoais; (c) relações familiares e sociais; (d) motivações.

As categorias foram criadas agrupando-se trechos que traziam informações semelhantes acerca dos aspectos investigados. $\mathrm{O}$ trabalho de análise foi realizado pela primeira autora e discutido com as demais até se chegar a um consenso sobre os resultados a serem apresentados no presente estudo.

\section{Resultados}

Caracterização dos Processos de Habilitação e Funcionamento das Equipes

A maioria dos participantes, quando questionados, relataram ter uma carga de trabalho grande, atendendo, em média, 20 processos por mês, e não exclusivos ao tema da infância. Muitos técnicos eram responsáveis, também, por atender à demanda de outros processos cíveis e criminais. Esse acúmulo, segundo a fala dos participantes, resultava em 
dificuldade de realizar uma prática mais profunda dos casos acompanhados.

Outro dado relevante foi em relação ao volume de processos de habilitação para adoção. A maioria dos profissionais comentou que o número de candidatos que buscam a habilitação é muito grande, chegando a perfazer cerca de um terço da carga de trabalho. Ao considerar que esses eram profissionais lotados no JIJ, é interessante pensar que a maior demanda de trabalho não se referia diretamente a medidas de proteção à criança, mas à avaliação de condições de candidatos para exercerem o papel de pai e mãe adotivos.

Em relação ao trabalho em equipe, do psicólogo em conjunto com o assistente social, também não foi relatada uniformidade nas práticas profissionais. Alguns profissionais afirmaram que faziam um trabalho integrado, inclusive podendo redigir um parecer conjunto, mas somente quando havia uma boa relação entre eles. Não foi referido por nenhum dos profissionais um estímulo em relação à discussão de caso. Também foi relatado que a discussão, quando acontecia, dava-se somente dentro da equipe técnica, não havendo muita possibilidade de discussão com o magistrado, ficando ele a cargo da decisão somente a partir dos laudos e relatórios redigidos pelos técnicos.

Em relação à multidisciplinaridade, os profissionais comentaram que não concebiam a avaliação psicológica e social como dissociadas, o que pode ser produtivo, considerando-se a complexidade envolvida no conteúdo a ser avaliado. Também foi relatado, por alguns profissionais, que não havia distinção entre conteúdos puramente sociais ou psicológicos, já que as temáticas abordadas pelas duas áreas muitas vezes se sobrepõem e essa troca pode ser muito positiva. A ideia, para alguns participantes, era de que as duas avaliações poderiam propiciar mais momentos de discussão, para que os candidatos à adoção pudessem esclarecer dúvidas e amadurecer o seu projeto adotivo a partir da visão de dois profissionais diferentes. Inclusive, foi possível perceber que não houve diferenças entre as falas dos psicólogos e dos assistentes sociais em relação ao que deveria ser investigado, ocorrendo sobreposição importante dos conhecimentos utilizados por ambas categorias.

Também foi possível identificar diferentes procedimentos executados para a coleta das informações. Nesse sentido, todos os profissionais referiram utilizar a entrevista como principal meio de coletar os dados relevantes e realizar sua avaliação. Essa entrevista pode ser considerada semiestruturada, com alguns tópicos que eles avaliam relevantes para o entendimento do caso. Todos relataram iniciar o processo com uma entrevista conjunta no caso dos casais e, conforme a necessidade, marcariam mais encontros conjuntos ou individuais. Em alguns casos, também, os profissionais sentiam a necessidade de entrevistar outros membros da família que não os candidatos, como nos casos de famílias que já tem filhos biológicos ou candidatos solteiros. $\mathrm{O}$ número médio de entrevistas que relataram realizar em cada processo foi entre duas e três.

A utilização de outros instrumentos de investigação variou muito entre os relatos dos participantes. Pode-se perceber que a escolha dos instrumentos ocorria conforme a demanda de cada caso e a segurança do profissional na avaliação daquele candidato especificamente. Dentre os assistentes sociais, o instrumento mais citado, além da entrevista, foi a visita domiciliar. Por meio dela, os profissionais relataram conseguir ter uma ideia da dinâmica de funcionamento do candidato.

Entre os psicólogos que participaram, apenas três mencionaram a utilização de algum teste projetivo, como o Teste Rorshach, mas somente quando sentiram dúvidas na avaliação. Apenas um profissional contou que sempre utilizava testagem e, nesse caso, instrumentos psicométricos, como, por exemplo, testes de avaliação da personalidade. Um profissional também fez referência ao uso de contatos com a rede de atendimento social e de saúde quando julgava necessário.

\section{Critérios Avaliados}

Sobre os critérios utilizados, foi possível apreender que a ideia geral do processo de habilitação para adoção não é encontrar o melhor candidato, mas alguém que tenha condições mínimas que serão descritas a seguir. A avaliação faz-se necessária em função das crianças que serão adotadas, para tentar garantir adotantes, de fato, habilitados a tornarem-se pais. Dentre essas condições mínimas referidas pelos participantes, foi possível identificar alguns tópicos comuns que serão descritos e discutidos mais profundamente.

\section{História de Vida}

A história pregressa - como o candidato se desenvolveu, como foi sua infância, como se deu a relação com a família de origem e como elaboraram situações traumáticas e crises do desenvolvimento - apareceu como um dos aspectos a ser avaliado: "O histórico de vida, todos os dados da familia pregressa, todos os dados assim de funcionamento, de dinâmica dessa pessoa, de dinâmica daquela 
familia de origem...” (P2); “nem sempre a história de vida é legal, mas ele vai contar que ele conseguiu superar." (P3).

$\mathrm{Na}$ história de vida, a relação com a família de origem durante o desenvolvimento e os modelos parentais também se mostraram importantes para a compreensão do processo de amadurecimento emocional dos candidatos, ou seja, como conseguiram se diferenciar da sua família de origem e se distanciar de maneira saudável, conseguindo alcançar esse novo estágio do ciclo vital: "Eu vejo cada modelo de família, como é que se deu essa separação. Porque tem gente que ainda está muito infantilizada, ligada a questões familiares e que tem que crescer mais para ter um filho." (P7); "[...] da dinâmica familiar, da história pregressa desses candidatos, das suas próprias familias, porque a gente vai tentar avaliar quais são as referências parentais para avaliar as suas condicões para o exercício dessa parentalidade.” (P17).

A trajetória escolar e profissional também despontou como critério avaliativo: "A história do trabalho, por que motivos que sairram, que entraram. Às vezes tem muita gente que sai muito dos trabalhos. Ou porque também ficaram um tempo significativo." (P18). Ainda, os profissionais relataram investigar questões de saúde física e psíquica: "Se teve algum problema de comportamento, porque tudo isso vai te montando o agora, né? Se tiveram alguns problemas de saúde, de saúde física ou saúde mental." (P18).

Por meio dos relatos, pode-se inferir que o objetivo principal dos técnicos judiciários é investigar o funcionamento psíquico e a dinâmica pessoal e de relacionamentos dos candidatos.

\section{Características Pessoais}

No relato dos participantes, também foi possível observar a análise das características pessoais dos candidatos, com destaque para a disponibilidade emocional e a capacidade afetiva: "Tem que estar realmente ciente do quanto ele vai precisar estar presente na vida dessa criança, não só em dar o nome dela no documento. Tem que ver o quanto essa pessoa está disposta a encarar esse desafio." (P10)

"Uma pessoa que tenha uma disponibilidade interior para acolher, no seu coração, uma outra pessoa e primar por seu desenvolvimento psíquico, social, afetivo e fazer, de certa forma, a continuidade, a perpetuação da espécie, a continuidade do mundo. [...]aquela capacidade interna de doação, de amor." (P13)

'E ser pai e mãe en acho que é isso aí, tu acolher uma criança no teu coração, quer ela tenha saído de ti, quer ela tenha entrado só no teu coração [...] Tu tens que ter aquela capacidade interna de doação, de amor." (P13).
Um tópico relevante refere-se ao quanto os candidatos relataram conseguir imaginar as mudanças que a chegada de uma criança seria capaz de fazer em suas vidas. Aqui foi avaliada a organização para a possível chegada do filho(a), além da flexibilidade frente às dificuldades (visto que as crianças irão demandar tal característica) e da capacidade de refletir e de elaborar as situações vivenciadas, como na questão da infertilidade:

'[...] a capacidade reflexiva, de ter 'insights' das situaçoes, por mais simples que seja a familia, né, por nem ser alfabetizada, mas a gente vê que tem sistemas que são, que trabalham muito bem, que estão ali adaptados ao contexto onde eles estão e para mim isso é o suficiente, né?" (P2)

\section{Relações Sociais e Familiares}

Os profissionais referiram considerar importante que os candidatos tivessem boas relações com a família de origem, a fim de avaliar um desejo de incluir essa criança no seu contexto familiar: "Então assim, eles trazem, por exemplo, que mantém relação com a família de origem até hoje, né? Claro, alguns moram longe, se telefonam, mas tu vês que tem um vinculo saudável com a família de origem." (P1); "[...] que queira incluir essa criança, realmente, na familia toda. Consiga perceber que a participação do avô, do tio, dos outros familiares vai fazer muito bem para essa criança, para ela se sentir pertencente, né." (P10)

As relações sociais foram citadas como importantes no sentido de conhecer se o candidato conseguiria abrir espaço para outros em sua vida e se articular com amigos, vizinhos, companheiros de clube e/ou outras crianças, por exemplo: "Quantos irmãos, se tem sobrinhos, como é que se relacionam com os sobrinhos... Então toda essa questão social eu também tento contemplar na entrevista."(P18). "Que tão inseridas socialmente, se frequentam uma igreja, se vão a um clube, se vão ao cinema, se vão ao teatro, se tem aula de música, se tem aula de dança, se gostam de se reunir com familiar $[\ldots] ”(\mathrm{P} 15)$

\section{Motivação}

A questão da motivação destacou-se como fundamental para os profissionais que verificam a aptidão de candidatos à adoção, sendo possível identificar motivações consideradas inadequadas e adequadas.

Como motivações inadequadas, os profissionais destacaram o lugar que será ocupado pela criança que esperam. Quando ela vem à família para ocupar qualquer outro lugar que não o de filho, isso é considerado problemático: 
"Olha, quando realmente eles não conseguem, ou quando o casal é totalmente disfuncional, [...] quando a adoção não é pra filiação, como eu te falei, aquela criança vai assumir um lugar que nem eles sabem me dizer exatamente o que que é.” (P2).

Também os desejos altruístas, de querer adotar para ajudar alguém ou fazer o bem, não são considerados adequados pelos profissionais: "Porque não adianta assim ó, vir, eles terem um desejo altruísta se é, se não tem esse desejo da maternidade, paternidade. Porque senão vai deixar uma lacuna na criança” (P14). Foi considerado inadequado, também, o desejo por alguém que venha a ocupar um lugar que está vago na vida do candidato, como no caso da morte de um filho anterior, ou um divórcio. Também nesses casos aparecem os casais no período do ninho vazio, em que os filhos já cresceram e saíram de casa: "[...] Claro, o que acontece é que, ao mesmo tempo [que] algumas pessoas chegam aqui e nos dizem, claramente, que querem um herdeiro on que querem uma companbia..." (P4).

Ainda, quando há uma pressão social para que o casal tenha filhos, também não é incentivada a adoção: "[...] é porque todo mundo tem filho e todo mundo pergunta quando vem a criança e a pessoa tem que ter, também, para, daqui a pouco, cumprir um padrão de que todos os casais têm de ter filhos [...]” (P13).

Quando perguntado o que um candidato precisa para ser considerado apto para ser pai ou mãe adotivos, os profissionais destacaram, basicamente, duas condições. Uma delas é o desejo de ter um filho, e a outra, o desejo de ser pai e mãe. Ambas se referem intimamente ao desejo que os candidatos têm de experimentar uma relação parental com uma criança, independentemente de não ter sido gerada por eles biologicamente.

O desejo de ter um filho pode ser entendido, a partir dos relatos dos profissionais, como a vontade genuína de ter um filho aceitando todas as dificuldades que essa escolha pode trazer. É o desejo de acolher uma criança e considerá-la como uma continuação. Nessa categoria, foram tratadas as questões do desejo relacionadas à satisfação de ter um filho e poder transmitir algo de bom a um descendente. Também, foram considerados os apontamentos que dizem respeito ao espaço interno que os candidatos são capazes de criar para a inclusão de um novo membro na família. Alguns trechos das falas dos participantes a seguir exemplificam essa questão: "Eu foco muito a questão do desejo, né, da preparação que esse casal vem faz̧endo internamente para poder ter essa criança" (P16). "Porque se o desejo é a filiação, é ter um filho, é isso que eu vou ter que centrar a minha análise, né" (P17).
O desejo de ser pai/mãe também despontou como motivação relevante, que consiste na vontade de dar continuidade à linhagem e transmitir valores e legados. Considera-se a adoção como uma possibilidade dos candidatos realizarem o seu desejo de serem pai e mãe por questões que dizem respeito à satisfação pessoal, de seus planos e dos papéis que desejam desempenhar na vida: "É tu poder contribuir como ser bumano para a vida de uma outra pessoa. Eu, como ser humano, tento deixar uma marca, a gente tem que deixar um legado" (P13). "Acho que se vê perspectiva de um ideal voltado para isso, pessoal e do casal [...]. Acho que já tem um terreno bem favorável para incluir uma criança, porque se está incluindo num projeto do casal, uma continuidade" (P5).

\section{Discussão}

O presente estudo teve como objetivo conhecer os critérios considerados pelos técnicos judiciários do Rio Grande do Sul nos processos de habilitação para adoção. A partir dos dados apresentados, foi possível compreender que o processo para adoção tem como meta mais do que uma avaliação das condições dos candidatos para receber uma criança em adoção. $\mathrm{O}$ trabalho é voltado, também, para a identificação dos motivos subjacentes à decisão de adotar.

Para os profissionais entrevistados, os pretendentes devem ter a motivação genuína de querer um filho e querer ser pai e mãe. Tais achados corroboram a literatura específica da área (Cecílio \& Scorsolini-Comin, 2018; Oliveira, Magalhães, \& Pedroso, 2013; Riede \& Sartori, 2013). Ainda, outras características relevantes foram mencionadas como critérios a serem considerados sobre os pretendentes, como: disponibilidade emocional, afetividade, capacidade de elaboração e superação de situações traumáticas, flexibilidade, boas relações com a família de origem e suporte social adequado, como sugerido por alguns autores (Cecílio \& Scorsolini-Comin, 2016; Paiva, 2004; Piermattei, Pace, Tambelli, D’Ornofrio, \& Folco, 2017). Todas essas características evidenciam a necessidade de sutileza, por parte do profissional, nas avaliações, o que torna esse trabalho ainda mais difícil.

Foi possível inferir que alguns profissionais percebiam a artificialidade desse processo de avaliação, já que é algo que difere muito da parentalidade biológica. Tendo em vista que a transição para a parentalidade é um processo tão complexo e uma das fases mais marcantes do ciclo vital, discute-se se poderia pensar no processo de habilitação para adoção como um espaço 
de reflexão, muito mais do que uma avaliação concreta de quem está apto ou não para ser pai e mãe e uma seleção de quem serão os melhores pais. Se eles serão bons pais ou não, somente o tempo e a convivência com a criança irão dizer, porque o papel parental é uma construção que se dá na relação (Baumkarten, Busnello, \& Tatsch, 2013). O indivíduo não nasce nem pai nem mãe, nem mesmo se torna somente com o nascimento de um bebê geneticamente relacionado a ele. É a relação com a criança que faz de uma mulher mãe e de um homem pai, e confere sentido às palavras maternidade e paternidade (Morelli et al., 2015). É preciso construir a parentalidade na relação com a criança bem como na relação que se estabelece entre os pais e a família de origem. Como apontou Zornig (2010), o bebê faz seus pais, construindo-os e parentalizando-os ao mesmo tempo em que é constituído por eles.

Todos os pais, adotivos ou biológicos, precisam aprender as demandas que a parentalidade exige (Cecílio \& Scorsolini-Comin, 2016). A história do filho é uma construção compartilhada em coautoria com os adultos, mas que se constrói a partir da história relacional dos seus pais (Zornig, 2010). A literatura aponta que a avaliação social e psicológica vista como um espaço de reflexão pode contribuir como uma preparação para a parentalidade dos candidatos (Sprince, Hindle, \& Shulman, 2008). Pensando sob essa perspectiva, o estudo psicossocial teria uma função de promoção de saúde e poderia auxiliar a prevenir possíveis problemas com relação à adoção, permitindo que os candidatos reflitam sobre vivências e sentimentos intensos, que talvez não tenham sido pensados anteriormente.

Nesse sentido, proporcionar um espaço para que os candidatos percebam as suas limitações e os seus reais desejos pode evitar um futuro desajustamento na relação com o filho. $O$ desajuste entre pais e filho adotivo pode culminar na devolução, o que pode ser entendido como uma reedição da história de abandono, trazendo sofrimento à criança (que retornará à instituição de acolhimento) e à família adotante (Morelli et al., 2015). A espera pela adoção deve ser compreendida como um momento de construção do papel parental (Cecilio \& Scorsolini-Comin, 2016; Morelli et al., 2015). Nesse processo, é importante que os pais possam lidar com todas as dificuldades e medos que a adoção pode abarcar, tonando-se maduros e convictos de seu desejo pelo filho adotivo.

Para que o sujeito se constitua enquanto tal, é necessário que haja um investimento de outros, geralmente dos pais e mães, que o reconheçam e lhe atribuam sentido, deem a ele um nome e um lugar. Isso, na adoção, começa a acontecer muito antes da chegada da criança. O processo de habilitação para adoção deve ser um lugar para refletir justamente sobre esse espaço que está sendo dado à criança que está por vir, possibilitando aos adotantes outras formas de "gestar" o filho (Paiva, 2004). Porém, é importante recordar que, mesmo sendo o tempo da espera pela chegada da criança algo que permite aos pais se prepararem para assumir novas funções (Cecílio \& Scorsolini-Comin, 2016), é somente no convívio com o filho que poderão exercer a parentalidade (Baumkarten et al., 2013).

Outra questão importante de se mencionar e que não se observou na fala dos participantes é o que foi proposto por Paiva (2004) ao colocar que as intervenções dos profissionais que trabalham com os pretendentes devem auxiliá-los a criar um sentido para a demanda da adoção. Segundo a autora, esse processo daria subsídios para a construção de um espaço psíquico na dinâmica da família. Por meio disso, seria possível provocar nos candidatos um desprendimento do "filho ideal" e a construção do "filho possível” (Chaves, 2010; Costa \& Kemmelmeier, 2013). As idealizações podem ser uma armadilha que, uma vez não atingidas, pode gerar dificuldades no vínculo (Riede \& Sartori, 2013) ou, ainda, para depressão pós-adoção (Foli, Lim, \& South, 2017). Quando essas expectativas não são trabalhadas, podem ser fatores de risco para devolução da criança (Riede \& Sartori, 2013). Nesse sentido, à medida que vão elaborando essa possibilidade, os candidatos são desafiados a passar da expectativa de "conseguir uma criança" para "adotar um filho", conseguindo ser mais flexíveis na escolha do perfil (Chaves, 2010).

Ainda, a literatura coloca como importante que os candidatos compreendam que todo esse processo é necessário como uma forma de proteção às crianças que irão para adoção (Costa \& Campos, 2003). Para isso, é fundamental que se estabeleça um vínculo com os profissionais que os estão avaliando, para que se crie uma relação de confiança. Segundo D'Andrea (2002), se os candidatos se sentem confortados na presença do técnico, estarão mais disponíveis para explicitar e enfrentar aspirações, medos, fantasias e preconceitos, compreendendo que estão em um espaço que pode auxiliá-los a amadurecer seus pensamentos. Esse momento poderia ajudar a, inclusive, refletir se a adoção é de fato a opção mais adequada para eles naquele momento (Levinzon, 2014), fazendo com que o processo de habilitação se configure como uma forma de proteção também às famílias adotantes. 
Esse vínculo, entre profissional e candidatos, também se mostra importante para que os pretendentes à adoção não percebam o processo como mais um empecilho no caminho para a parentalidade (Sprince et al., 2008), já que para se esclarecerem todos os quesitos necessários para embasar a decisão judicial, não são raras as vezes em que eles são solicitados a falar sobre questões difíceis e sofridas de seu desenvolvimento. Além do que, grande parte dos candidatos já passou por tratamentos dolorosos, fracassos e frustrações na tentativa de exercerem a parentalidade biológica (Riede \& Sartori, 2013). Em virtude disso, famílias que passaram por esse processo relataram que o perceberam como um "vasculhamento" de sua vida, gerando um sentimento de superexposição (Costa \& Campos, 2003). Apesar disso, sabe-se que uma boa avaliação é fundamental para esclarecer os candidatos, que podem não conseguir perceber as suas limitações por estarem tão desejosos de um filho.

A fim de que se consiga construir essa relação, é necessário que os profissionais saibam separar-se de seus próprios modelos de "pais ideais" (D'Andrea, 2002). É importante que os técnicos consigam compreender todas vicissitudes do processo de construção da parentalidade para que consigam prover um espaço de atenção e reflexão a esses candidatos, visando proteger a criança em situação de abandono, mas também promover a saúde desses pais e da futura família. Para os profissionais, além da necessidade de formação, é importante que tenham condições de compreender as emoções complicadas e conflitantes dos candidatos, valorizando seus sentimentos para favorecer um ambiente de manifestações íntimas ligadas à motivação de adotar (Riede \& Sartori, 2013).

\section{Considerações Finais}

Sabe-se que esses resultados não esgotam a questão, mas podem trazer contribuições importantes aos profissionais que se deparam com pretendentes à adoção em sua prática. Em função disso, enfatiza-se a necessidade de se considerar cada filiação como única (Paiva, 2004), principalmente sob o ponto de vista dos profissionais que trabalham com adoção. Esse questionamento se faz importante quando também se considerada a artificialidade de um processo de avaliação de pretendentes à adoção, que são colocados na situação de provar suas condições para a parentalidade, algo que não acontece na filiação biológica.
Como discutido anteriormente, mesmo a criança sendo fruto de um investimento parental, a parentalidade se constrói na relação diária com ela, fazendo com que os pais se tornem pais. Por isso, é possível questionar se o processo de habilitação para adoção é mesmo um fator preditor para o estabelecimento de um vínculo parental saudável e se é sensível para avaliar as motivações adequadas ou inadequadas. Além disso, cabe o questionamento - e a possibilidade de investigações futuras - se candidatos que chegam ao juizado com motivações consideradas inadequadas apresentarão necessariamente prejuízos na relação com a criança. Como proposto por Zornig (2012), é necessário considerar a influência da realidade psíquica de cada um dos pais, as transformações ocorridas nas formas de parentalidade de uma determinada cultura, assim como a importância das interações e trocas entre pais e filhos, para definir o processo de transição à parentalidade e favorecer o funcionamento das famílias na atualidade.

Entende-se que este estudo possui limitações na medida em que observou somente a visão dos profissionais acerca dos processos de habilitação para adoção, de maneira qualitativa. Sabe-se que estudos qualitativos auxiliam em uma compreensão mais profunda dos fenômenos, mas não permitem generalização dos resultados. Futuros estudos podem vir no sentido de compreender como as famílias vivenciam essas avaliações, bem como a visão dos operadores do Direito acerca desse processo, ampliando a fonte de dados e permitindo triangulação. Além disso, outra limitação importante foi ter investigado somente a realidade do Rio Grande do Sul. Como um segmento, essa análise poderá ser realizada em outras regiões do país, para a compreensão mais global do fenômeno investigado.

Outra questão que pode ser levantada diz respeito ao tempo que os candidatos habilitados à adoção esperam a criança após sua inclusão no Cadastro Nacional de Adoção, ou seja, após a habilitação. É possível questionar se as mudanças sofridas pelas famílias ao longo desse tempo de espera mantêm elas ainda adequadas à adoção. Estudos longitudinais poderiam contribuir para investigar essa questão.

Apesar de ser clara a importância de uma preparação psicossocial dos candidatos à adoção, a crescente demanda de trabalho em função da falta de recursos humanos nas instituições judiciárias pode ser um empecilho a um trabalho mais aprofundado com os candidatos. Além disso, a falta de uma preparação específica pode implicar na falta de uniformidade e especificidade no trabalho com a adoção. Em função 
disso, espera-se que estudos como este, que venham a problematizar a questão, possam trazer subsídios à prática profissional e auxílio à saúde mental e à construção de vínculos dessas novas famílias.

\section{Referências}

Bardin, L. (2011). Análise de conteúdo. São Paulo: Edições 70 .

Baumkarten, S. T., Busnello, F. \& Tatsch, D. C. (2013). Adoção: Conhecendo as expectativas e os sentimentos dos pais do coração. Perspectivas em Psicologia, 17(2), 03-19. Recuperado de http://www.seer.ufu. br/index.php/perspectivasempsicologia/article/ view/27899/15363

Cecílio, M. S., \& Scorsolini-Comin, F. (2016). Parentalidades adotiva e biológica e suas repercussões nas dinâmicas conjugais. Psicologia: Ciência e Profissão, 36(1), 171-182. doi: 10.1590/1982-3703003832015

Cecílio, M. S., \& Scorsolini-Comin, F. (2018). Avaliação de candidatos pretendentes no processo de habilitação para adoção: Revisão da literatura. Psico-USF, 23(3): 497-511. doi: 10.1590/1413-82712018230309

Chaves, V. P. (2008). Adoção e homossexualidade. Em Conselho Federal de Psicologia (Eds.). Cartilha da adoção (pp. 35-40). Recuperado de http://site.cfp. org.br/wp-content/uploads/2008/08/cartilha_ adocao.pdf

Chaves, V. P. (2010). Algumas informações sobre adoção no Brasil. Em A. Hilgemann (Ed.). Adoção: duas mães para uma vida (pp. 127-137). Porto Alegre: Editora Rígel.

Costa, L. T. M. \& Kemmelmeier, V. S. (2013). O olhar de futuros pais sobre o processo de adoção. Psicologia Argumento, 31(72), 187-196. Recuperado de http://www2.pucpr.br/ reol/index.php/pa?dd1 = $7619 \& \mathrm{dd} 2=5242 \& \mathrm{dd} 3=\& \mathrm{dd} 99=\mathrm{pdf}$

D'Andrea, A. (2002). O casal adotante. Em M. Andolfi (Ed.). A crise do casal: Uma perspectiva sistêmico-relacional (pp. 233-248). Porto Alegre: Artmed.

Estatuto da Criança e do Adolescente (1990). Recuperado de http://www.planalto.gov.br/ccivil_03/ leis/18069.html

Foli, K., Lim, E., \& South, S. (2017). Longitudinal analyses of adoptive parents' expectations and depressive symptoms. Research in Nursing and Health, 40(6), 564-574. doi: 10.1002/nur.21838

Laville, C., \& Dione, J. (1999). A construção do saber: Manual de metodologia da pesquisa em ciências humanas. Porto Alegre: Artes Médicas.

Levinzon, G. K. (2014). Tornando-se pais: A adoção em todos os seus passos. São Paulo: Casa do Psicólogo.

Morelli, A. B., Scorsolini-Comin, F., \& Santeiro, T. V. (2015). O "lugar" do filho adotivo na dinâmica parental: Revisão integrativa da literatura. Psicologia Clínica, 27(1), 175-194. doi: 10.1590/0103-56652015000100010

Oliveira, M., Magalhães, C., \& Pedroso, J. (2013). Família adotante: Estudo de caso de adoção tardia. Revista Brasileira de História e Ciências Sociais, 5(9), 22-36. Recuperado de https://www.rbhcs.com/ rbhcs/article/view/174

Paiva, L. D. (2004). Adoção: Significados e possibilidades. São Paulo: Casa do Psicólogo.

Piermattei, C., Pace, C. S., Tambelli, R., D’Onofrio, E., \& Di Folco, S. (2017). Late adoptions: attachment security and emotional availability in motherchild and father-child dyads. Journal of Child and Family Studies, 26(8), 2114-2125. doi: 10.1007/ s10826-017-0732-6

Rampage, C., Eovaldi, M., Ma, C., Foy, C. W., Samuels, G. M., \& Bloom, L. (2016). Famílias adotivas. Em Walsh, Froma. Processos Normativos da Família: Diversidade e Complexidade. Porto Alegre: Artmed.

Reppold, C. T., Chaves, V. P., Nabinger, S. B., \& Hutz, C. S. (2005). Aspectos práticos e teóricos da avaliação psicossocial para habilitação à adoção Em Hutz, C. S. (Eds.). Violência e risco na infância e adolescência: pesquisa e intervenção (pp. 43-70). São Paulo: Casa do Psicólogo.

Riede, J. E., \& Sartori, G. L. Z. (2013). Adoção e fatores de risco: Do afeto à devolução das crianças e adolescentes. Perspectiva, 37(138), 143-154. Recuperado de http://www.uricer.edu.br/site/pdfs/perspectiva/138_354.pdf

Robson, C. (2002). Real world research: a resource for social scientists and practitioner-researchers (2nd ed.). Malden: Blackwell.

Silva, P. S. (2015). Os processos de habilitação para adoção segundo técnicos judiciários do Rio Grande do Sul 
(Dissertação de mestrado). Programa de Pós-Graduação em Psicologia do Desenvolvimento, Instituto de Psicologia, Universidade Federal do Rio Grande do Sul. Porto Alegre, Brasil.

Sprince, J., Hindle, D., \& Shulman, G. (2008). The network around adoption: The forever family and the ghosts of the dispossessed (pp. 99-114). Abingdon: Routledge.

Zornig, S. M. A. J. (2010). Tornar-se pai, tornar-se mãe: O processo de construção da parentalidade. Tempo psicanalitico, 42(2), 453-470. Recuperado de http:// pepsic.bvsalud.org/pdf/tpsi/v42n2/v42n2a10.pdf

Zornig, S. M. A. J. (2012). Construção da parentalidade: Da infância dos pais ao nascimento do filho. Em C. A. Piccinini \& P. Alvarenga (Eds.), Maternidade e paternidade: A parentalidade em diferentes contextos (pp. 17-34). São Paulo: Casa do Psicólogo.

Recebido em: 21/06/2018

Reformulado em: 27/09/2019

Aprovado em: 11/10/2019

Sobre as autoras:

Patricia Santos da Silva é Psicóloga (Universidade Federal de Ciências da Saúde de Porto Alegre - UFCSPA), Mestre, Doutora e Pós-Doutoranda do Programa Nacional de Pós-Doutorado da CAPES no Programa de Pós-Graduação em Psicologia da Universidade Federal do Rio Grande do Sul - UFRGS, Especialista em Terapia Sistêmica com Indivíduos, Casais e Famílias (Centro de Estudos da Família e do Indivíduo - CEFI).

ORCID: https://orcid.org/0000-0002-4363-6821

E-mail:patis.psico@gmail.com

Monique Souza Schwochow é Psicóloga (Universidade Federal do Rio Grande - FURG), Mestre e Doutoranda em Psicologia (Universidade Federal do Rio Grande do Sul - UFRGS) e Especialista em Infância e Família (UFRGS) e em Terapia Sistêmica com Indivíduos, Casais e Famílias (Centro de Estudos da Família e do Indivíduo - CEFI).

ORCID: https://orcid.org/0000-0002-4424-5005

E-mail: moniqueschwochow@gmail.com

Gabriela de Faria Resmini é Psicóloga (Universidade Federal do Rio Grande do Sul - UFRGS), Mestre em Psicologia (UFRGS) e especializanda em Terapia Sistêmica com Indivíduos, Casais e Famílias (Centro de Estudos da Família e do Indivíduo - CEFI).

ORCID: https://orcid.org/0000-0002-6833-2904

E-mail: gabiresmini@gmail.com

Giana Bitencourt Frizzo é Psicóloga, Professora Departamento de Psicologia do Desenvolvimento e Personalidade e do Pós-graduação em Psicologia do Instituto de Psicologia da UFRGS.

ORCID: https://orcid.org/0000-0001-8106-4441

E-mail gifrizzo@gmail.com

Contato com as autoras:

Av. Paulo Gama, 110 - Bairro Farroupilha

Porto Alegre-RS, Brasil

CEP: 90040-060 